\title{
AMPHOTERICIN B ASSOCIATED WITH TRIGLYCERIDE-RICH NANOEMULSION: STABILITY STUDIES AND IN VITRO ANTIFUNGAL ACTIVITY
}

Fabíola Branco Filippin e Liliete Canes Souza*

Departamento de Análises Clínicas, Centro de Ciências da Saúde, Universidade Federal de Santa Catarina, 88040-970

Florianópolis - SC, Brasil

Raul Cavalcante Maranhão

Instituto do Coração, Hospital das Clínicas, Av. Dr. Enéas Carvalho de Aguiar, 44, 05403-000 São Paulo - SP, Brasil

Recebido em 16/5/07; aceito em 27/9/07; publicado na web em 2/4/08

\begin{abstract}
Amphotericin $\mathrm{B}(\mathrm{AB})$ is the standard drug for invasive fungal infection therapy. It has a broad spectrum of activity and it is the best antifungal available against most yeasts and molds. Its therapeutic use, however, is limited by significant side effects, leading to a low therapeutic index when it is used as the traditional formulation (Fungizone $®$ ). Due to self-association, $A B$ can form pores in cholesterol-containing membranes. We propose a triglyceride-rich nanoemulsion as a delivery system for $\mathrm{AB}$ in low levels of aggregation to reduce the toxicity against host cells.
\end{abstract}

Keywords: amphotericin B; lipid nanoemulsion; delivery system.

\section{INTRODUCTION}

Amphotericin $\mathrm{B}(\mathrm{AB})$ is the standard drug for therapy of invasive fungal infections. $\mathrm{AB}$ has a broad spectrum of activity against most yeasts and molds, but its parenteral administration is limited by toxic effects that include fever, chills, nausea, vomiting and hypokalaemia, resulted from treatment with traditional preparations (micelles mixed with sodium deoxycholate). ${ }^{1,2}$ In addition, symptoms of nephrotoxicity, including elevated serum creatinine and urea levels, often become apparent upon prolonged administration, which leads to a low therapeutic index. ${ }^{1,3} \mathrm{AB}$ exerts a fungicidal effect by binding irreversibly to ergosterol, a component found in fungal cell, disrupting the membrane and causing cell death. ${ }^{4}$ Due to its broad spectrum of activity, $\mathrm{AB}$ has been considered the treatment of choice for invasive fungal infections for the past 30 years.

The therapeutic potential of $\mathrm{AB}$ and other polyene antibiotics is determined by their affinity for cholesterol and ergosterol, the principal sterols in eucaryote cell membranes. The selectivity for these sterols depends on the aggregation state of $\mathrm{AB}$. Monomeric $\mathrm{AB}$ associates with the sterols in fungal cell membranes, whereas self-associated $\mathrm{AB}$ can also form pores in cholesterol-containing membranes, leading to toxicity towards host cells. ${ }^{5}$

Lipid formulations commercially available share the same spectrum of action and reduce most side effects representing a significant advance in $\mathrm{AB}$ delivery. These formulations include $\mathrm{AB}$ lipid complex, $\mathrm{AB}$ colloidal dispersion and small unilamellar vesicle formulations of $\mathrm{AB}$. Despite the fact that activity seems superior to the traditional formulation, the dose and cost effectiveness need further study. ${ }^{6}$

The development of new lipid formulation for intravenous administration of $\mathrm{AB}$ might therefore be desirable, presenting monomeric forms and preserved activity against yeasts and moulds. In this study, we developed a stable triglyceride-rich nanoemulsion containing $\mathrm{AB}$, with strong evidence that its applicability could be more successful than conventional formulations. We have hypothesized that caprylic/capric triglyceride-rich nanoemulsion

*e-mail: liliete@ccs.ufsc.br could solubilize $\mathrm{AB}$ and reduce its self-aggregation state in solution. In particular, the present paper describes the production of a nanoemulsion containing lipid components, its physicochemical characterization, in vitro activity against Candida albicans and stability during 6-month storage.

\section{EXPERIMENTAL}

\section{Materials}

AB powder (86.04\% pure) was purchased from Bristol-MyersSquibb (São Paulo, Brazil), AB in deoxycholate (AB-DOC) (Fungizone ${ }^{\circledR}$, Bristol-Myers-Squibb) was purchased from a hospital pharmacy, soya bean lecithin, and cholesterol was obtained from Sigma Chemicals (St. Louis, MO). Miglyol 812 N® was kindly provided by Sasol Corp. (Germany). The solvents and reagents used were purchased from Sigma Chemicals (St. Louis, MO) and Merck (Rio de Janeiro, Brazil) and were the highest commercially available grade and were used without further purification. RPM1 1640 medium and morpholinepropane sulfonic acid (MOPS) were from Sigma Chemical (St. Louis, MO). Candida albicans serotype A (3153) was obtained from The London School of Higyene of Tropical Medicine (UK).

\section{Preparation of the triglyceride-rich nanoemulsion containing AB (AB-N)}

AB-N was prepared as previously described by Souza et al. $^{7}$ with some modifications. Briefly, caprylic/capric triglyceride (70\%), soya bean lecithin (27\%), and cholesterol (3\%) were dissolved in chloroform-methanol (2:1, v/v) and AB powder was added (100 $\mathrm{mg}$ ) to perform $\mathrm{AB}$ : lipids at a molar ratio of 1:11. The mixture was dried under nitrogen flow and kept under vacuum overnight in order to remove organic solvent. Follow, $40 \mathrm{ml}$ of TRIS- $\mathrm{HCl}$ buffer (0.01 M, pH 8.05) was added and emulsified with a probe-type sonicator for $30 \mathrm{~min}$ at $50-60{ }^{\circ} \mathrm{C}$. The final dispersion was obtained after centrifugation at $150,000 \mathrm{~g}$ for $30 \mathrm{~min}$ to precipitate titanium and non-incorporated drug. The nanoemulsion was filtrated through 
a $0.22 \mu \mathrm{m}$ membrane and storage at 4 and $25{ }^{\circ} \mathrm{C}$ protected from light. The non-incorporated drug was used in order to quantify the concentration of $\mathrm{AB}$ into $\mathrm{AB}-\mathrm{N}$.

\section{Physicochemical characterization of AB-N}

In order to evaluate the solubilizing power of the produced formulations, the non-incorporated drug was quantitative determined by UV spectrophotometry, using methanol as organic solvent. $\mathrm{AB}$ incorporation into nanoemulsion was calculated by subtracting the inicial amount of $\mathrm{AB}$ added from the quantity of insoluble drug recovery. Particle size of AB-N (mean diameter) was performed by using a ZetaPlus Analyser 90Plus (Brookhaven Instruments Corporation, NY, USA) equipped with a $35 \mathrm{~mW}$ laser light scattering at $90^{\circ}$. Aliquots were diluted in TRIS-HCl buffer (1:250) for all determinations. $\mathrm{pH}$ measurements were performed by a selective ion $\mathrm{pH}$ meter (Athos Intrumentação Ind, São Paulo) monthly. The particle size and $\mathrm{pH}$ measurements were determined just after AB-N preparation and then at intervals until up to 6 months. Absorption spectra $(300-450 \mathrm{~nm})$ were obtained by dispersing the formulations in glucose 5\%, resembling injectable administration, using a Perkin-Elmer Lambda UV-visible spectrometer. For ABDOC spectrum, the formulation was prepared according to the manufacturer. All spectra, particle sizing and $\mathrm{pH}$ measurements were obtained at room temperature $\left(25^{\circ} \mathrm{C}\right)$.

\section{Chemical stability during storage}

Stability studies were conducted at $0,1,2,3,4,5$ and 6 months in independent experiments with aliquots storage at 4 and $25{ }^{\circ} \mathrm{C}$ protected from light. $\mathrm{AB}$ content was evaluated by quantitative determination of non-incorporated drug (insoluble drug in the aqueous phase) extracted by centrifugation at $15,000 \mathrm{~g}$ for $20 \mathrm{~min}$. After centrifugation, the supernatant was discarded and the remaining insoluble drug, if any, washed three times with $2 \mathrm{~mL}$ of distilled water. The washed drug crystals were dissolved in methanol and quantified by UV spectrophotometry (404 nm) using calibration curves. The system was validated by adding a defined amount of drug suspension to the nanoemulsion and separating the particles again, being the recovery $102 \%$.

\section{Determination of in vitro activity of AB-N against Candida albicans}

Susceptibility testing was performed in RPM1 1640 medium without L-glutamine and without sodium bicarbonate and buffered to $\mathrm{pH} 7.0$ with $0.165 \mathrm{M}$ MOPS. Sterile 96-well microplates were used. Stock solutions of the AB-N was diluted with RPM1 1640 to obtain the final concentrations as a recommendation to minimize systematic pipetting error. ${ }^{8}$ Final drug concentrations were 0.005 to $12.5 \mathrm{mg} / \mathrm{L}$. Some wells served as the growth control and sterility check. The Candida isolates ( ${ }^{\circ} 3153$ serotype A) were cultured on Sabouraud dextrose agar for $24 \mathrm{~h}$ at $36^{\circ} \mathrm{C}$. The inoculum suspension was prepared by suspending colonies in $5 \mathrm{~mL}$ of sterile $0.85 \%$ saline. The resulting suspension was vortexed for $15 \mathrm{~s}$, and the cell density was adjusted to $0.5 \mathrm{McFarland}$ Standard. The suspensions were diluted 1:100 with sterile saline, followed by dilution 1:100 with RPMI 1640. One hundred microliters of the yeast suspension was added to each well, resulting in the desired final drug concentration and inoculum size. The microplates were incubated at $36{ }^{\circ} \mathrm{C}$ without agitation and read after $24 \mathrm{~h}$. A solvent control, organism control and medium control were performed simultaneously to check the growth inhibiting activity, organisms and sterility of broth medium.
The MIC was defined as the minimum concentration of $\mathrm{AB}$ that shows a full inhibition of the fungus in the well, examined by naked eyes and confirmed by an inverted microscope $(40 \mathrm{x})$. Susceptibility testing of $\mathrm{AB}-\mathrm{N}, \mathrm{AB}-\mathrm{DOC}$, and $\mathrm{AB}$ powder in dimethyl sulfoxide (DMSO) were performed in triplicate. For this test, formulations were storage over a 6-month period at $4{ }^{\circ} \mathrm{C}$ and were compared monthly with freshly prepared commercial preparations of AB-DOC and $\mathrm{AB}$ powder in DMSO. $\mathrm{AB}$ dissolved in DMSO was also diluted with phosphate buffered saline (PBS) $\mathrm{pH} 6.8$, giving DMSO content less than $1 \%$.

\section{RESULTS}

\section{Physicochemical characterization of AB-N}

The prepared AB-N formulation aimed for parenteral administration. Thus particle size and particle size distribution are crucial parameters for safe administration of such formulation. The mean particle size and size distribution of $\mathrm{AB}-\mathrm{N}$ nanoparticles were determined by dynamic light scattering in fresh and in 6-monthstorage formulations $\left(4\right.$ and $25^{\circ} \mathrm{C}$ ). The results are showed in Figure 1 and 2. The mean particle size diameter was $137.2 \mathrm{~nm}$ just after preparation and mean size of droplets showed an increase

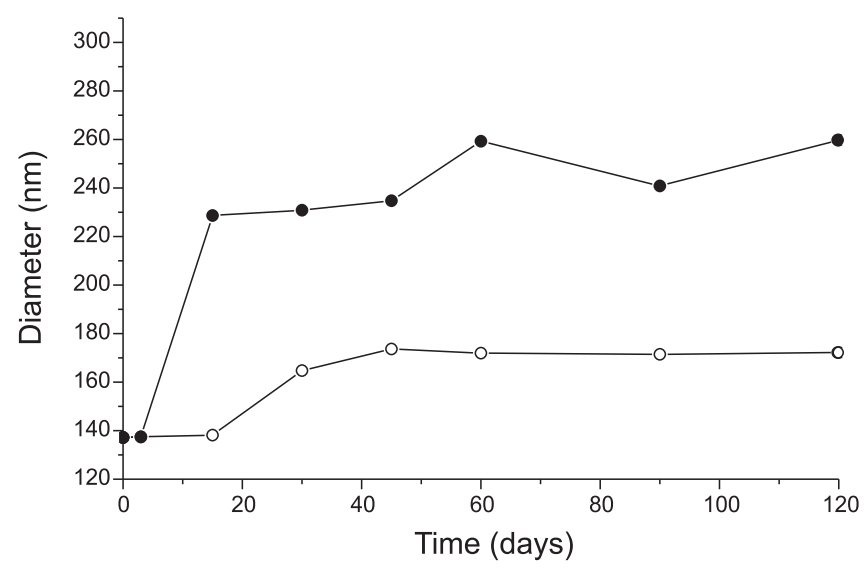

Figure 1. Particle diameter performed by laser light scattering. Nanoemulsions were analyzed just after preparation and in intervals until 6 months storage at $4{ }^{\circ} \mathrm{C}(\mathrm{O})$ and at $25^{\circ} \mathrm{C}(\bullet)$

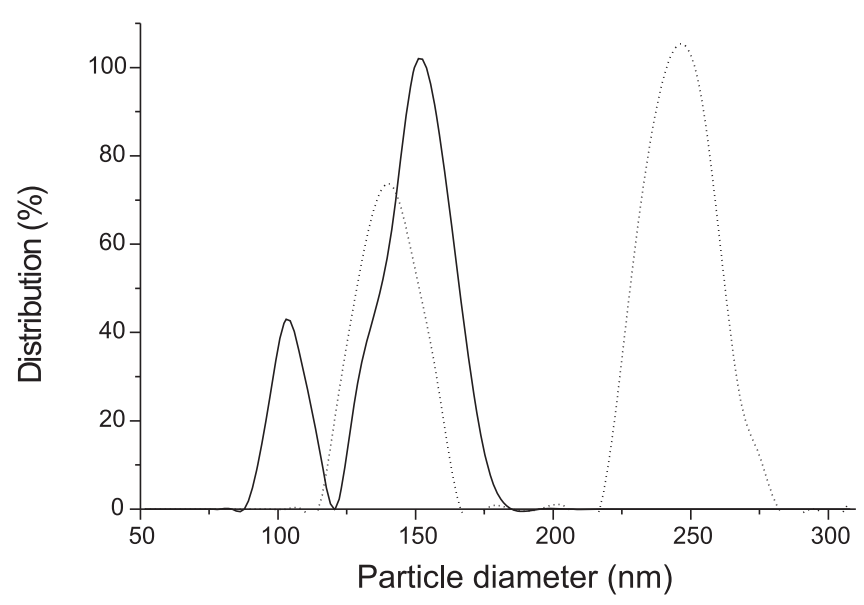

Figure 2. Dimensional distributions of $A B-N$ just after preparation (straight line), and 6-month storage at $4{ }^{\circ} \mathrm{C}$ (dot line) expressed as percentage of distribution, determined by laser light scattering 
$(\mathrm{p}=0.001)$ after 6 month-storage at $4(26.2 \%)$ and at $25^{\circ} \mathrm{C}(115.1 \%)$. The $\mathrm{pH}$ measurements were performed on $\mathrm{AB}-\mathrm{N}$ just after preparation and than monthly until 6 months, illustrated in Figure 3. No differences was found in $\mathrm{pH}$ values that ranged from 6.2 to 6.6 during storage at 4 and $25^{\circ} \mathrm{C}(\mathrm{p}>0.05)$.

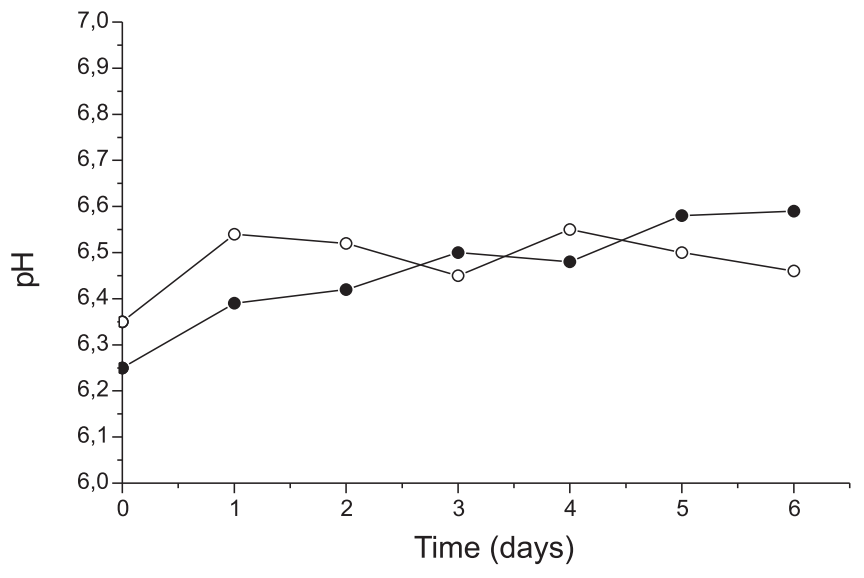

Figure 3. $\mathrm{pH}$ values of $\mathrm{AB}-\mathrm{N}$ storage at $4{ }^{\circ} \mathrm{C}(\mathrm{O})$ and $25^{\circ} \mathrm{C}(\bullet)$ in function of time

\section{Dispersion of $\mathrm{AB}-\mathrm{N}$ in glucose $5 \%$}

The UV-vis spectroscopy was used to investigate the aggregation state of $\mathrm{AB}$ associated to the particles of the nanoemulsion (Figure 4). The absorbance spectrum of $\mathrm{AB}$ in methanol representing the monomeric form, showed high intensity peaks at 405, 382, and $363 \mathrm{~nm}$ and lower intensity peak at $345 \mathrm{~nm}$. The absorbance spectrum of AB-DOC (Fungizone $\left.{ }^{\circledR}\right)$, which represents the self-aggregation state of $\mathrm{AB}$, showed a broad peak with high intensity at $326 \mathrm{~nm}$ and less intense peaks at 365, 385, and $408 \mathrm{~nm}$. The absorbance spectrum of AB-N in glucose $5 \%$ showed a peak at 368 and $425 \mathrm{~nm}$.

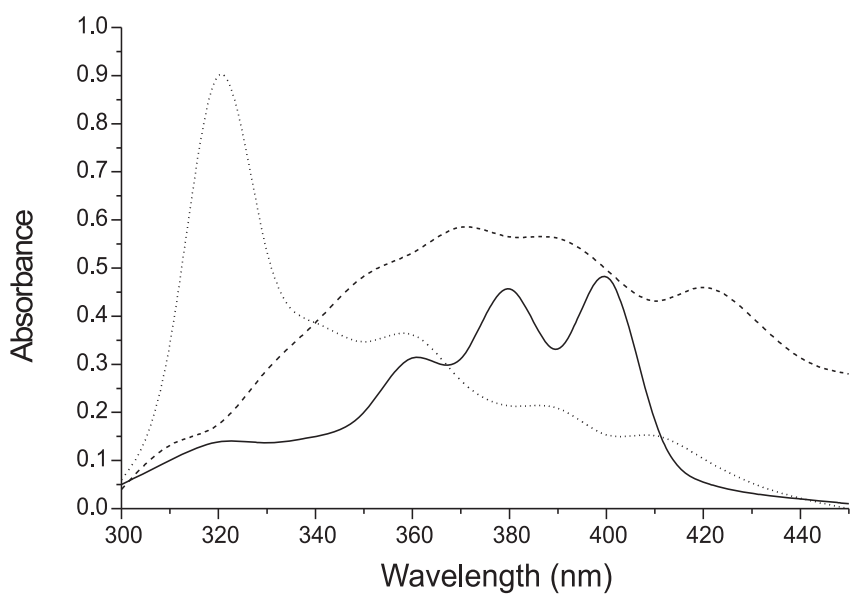

Figure 4. Evolution of absorbance spectra of $A B$ in different formulations at $1.5 \times 10^{-5} \mathrm{M}: A B$ in methanol (straight line), and $A B-D O C$ (dash line) and $A B$ $N$ in glucose $5 \%$ (dot line)

\section{AB content}

In order to evaluate the solubilizing power of the produced formulation and its chemical stability, the $\mathrm{AB}$ solubility was expressed by $\mathrm{AB}$ as function of time, expressed as percentage of initial drug content. The fresh preparation incorporated $98 \%$ of $\mathrm{AB}$ initial concentration and could maintain about $90 \%$ of $\mathrm{AB}$ in 6 months. Figure 5 shows the lost of $\mathrm{AB}$ content in formulations storage at 4 and $25{ }^{\circ} \mathrm{C}$.In both storage conditions, no $\mathrm{AB}$ lost were detected at sixth month showing a chemical equilibrium between $\mathrm{AB}$ and lipid components. Finally, it was found that in the case of $\mathrm{AB}-\mathrm{N}$ at $4{ }^{\circ} \mathrm{C}$, drug decrease was higher than $\mathrm{AB}-\mathrm{N}$ at $25^{\circ} \mathrm{C}$.

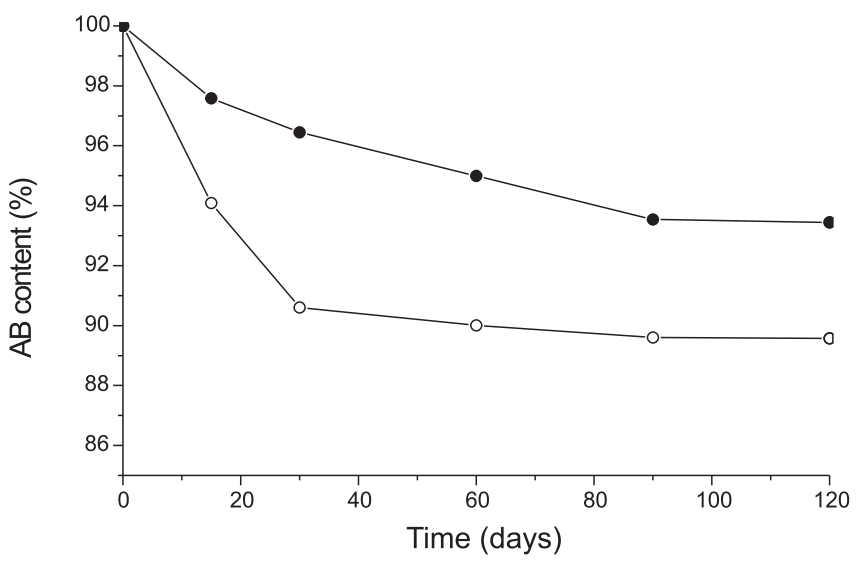

Figure. 5. Lost of $A B$ content in $A B-N$ storage at $4{ }^{\circ} \mathrm{C}(\bigcirc)$ and $25^{\circ} \mathrm{C}$ (•) as a function of time. Data represent percentage determinations performed by $U V$ spectroscopy at $404 \mathrm{~nm}$

\section{Susceptibility test of AB-N}

The in vitro antifungal activity of $\mathrm{AB}-\mathrm{N}$ was evaluated during 6-month storage at $4{ }^{\circ} \mathrm{C}$. The MIC data of AB in DMSO, AB-DOC and $\mathrm{AB}-\mathrm{N}$ is summarized in Table 1 . Our results showed that $\mathrm{AB}-\mathrm{N}$ could maintain the activity against Candida albicans during 6-month storage (MIC $0.03 \mu \mathrm{g} / \mathrm{mL}$ ), showing a greater activity than ABDOC (MIC $0.06 \mu \mathrm{g} / \mathrm{mL}$ ). The basis for the low MIC of AB-N compared with that of $\mathrm{AB}-\mathrm{DOC}$ is unclear, but the lipid components may be enhanced interaction of $\mathrm{AB}$ at a membrane level of fungi.

Table 1. Minimal inhibitory concentration (MIC) of AB in different formulations against Candida albicans

\begin{tabular}{lcc}
\hline Sample & \multicolumn{2}{c}{ MIC $(\mu \mathrm{g} / \mathrm{mL})$} \\
$\begin{array}{c}\text { Fresh } \\
\text { preparation }\end{array}$ & $\begin{array}{c}\text { 6-month } \\
\text { storage }\end{array}$ \\
\hline AB in DMSO & 0.12 & a \\
AB-DOC & 0.06 & a \\
AB-N & 0.03 & 0.03 \\
\hline
\end{tabular}

a not performed

\section{DISCUSSION}

Amphotericin B is poorly soluble in water and can be successfully incorporated into the lecithin layer of a lipid carrier system by sonication. The aim of new $\mathrm{AB}$ formulation is to reduce the toxicity of this potentially useful antifungal drug. Many studies have suggested that this toxicity is related to the physicochemical state of the drug, and particularly to self-associated forms, which are able to complex cholesterol in mammalian cell membranes. We have previously demonstrated an effective incorporation of $\mathrm{AB}$ in a chylomicron-like nanoemulsion with favorable findings. ${ }^{79}$ Our previously formulation was designed with high-cost lipid components dissolved in DMSO whereas in AB-N it was used 
alternative and biodegradable materials. AB-N can act as carrier system composed by coconut triglyceride, cholesterol and soybean lecithin in order to reduce self-aggregation state.

Experimental evidence gathered has shown that a close correlation exists between the aggregation state of $\mathrm{AB}$ in the vehicle and its toxicity in the site of infection. ${ }^{10,11}$ Therefore, various formulations of monomeric or preferably, slightly aggregated $A B$ have been developed. Kawabata et al. ${ }^{12}$ have previously demonstrated that a new formulation, micelles containing lysophosphatidylcholine and $\mathrm{AB}$, monomerized more favorably than formulations such as lipossomal formulations.

Spectra were recorded for the AB-N diluted in glucose $5 \%$ to give a final $\mathrm{AB}$ concentration of $1.5 \times 10^{-5} \mathrm{M}$. For that ratio, bands between 425 and $368 \mathrm{~nm}$ were obtained and it was similar to monomeric states of $\mathrm{AB}$ bound with phospholipids reported by Tabosa do Egito et al. ${ }^{13}$ (Figure 4). These spectra showed qualitative differences as those reported by Bolard et al. ${ }^{5}$ for $\mathrm{AB}$ in the monomeric and aggregate form. Using diluted $\mathrm{AB}$ in DMSO, they observed peaks in the 409,385 and $347 \mathrm{~nm}$ correspondent to monomeric form, whereas AB-N shift these bands to others ascribed in the presence of lipids. A difference in the aggregation state between $\mathrm{AB}-\mathrm{DOC}$ and $\mathrm{AB}-\mathrm{N}$ was observed with evidence of $\mathrm{AB}$ self-association (absorption band at $344 \mathrm{~nm}$ ) for AB-DOC.

The phospholipids, or lecithins, used in the preparation of most parenteral emulsions are quite heterogeneous materials, acting as emulsifiers leading to long-term stability formulations. ${ }^{14}$ The presence of a drug in the emulsion can considerably alter its behavior. Fortunately, the drug effect can often be predicted with knowledge of the physicochemical properties of the drug. AB may adsorb to the interface but will not normally influence surface charge. Therefore, this behavior is only valid at specific $\mathrm{pH}$, which suggests that $\mathrm{pH}$ measurements are the major tool to control this aspect of drug-containing nanoemulsion. ${ }^{15}$ According to Floyd, ${ }^{16}$ the optimum $\mathrm{pH}$ of the finished nanoemulsion is in the general range of 6-7 and low $\mathrm{pH}$ (values lower than 5) should be avoided as the electrostatic repulsion between particles is decreased, resulting in an increased globule size and coalescence. In addiction, neutral $\mathrm{pH}$ minimizes lecithin hydrolysis. The $\mathrm{pH}$ values ranged from 6.2 to 6.6 during storage at 4 and $25{ }^{\circ} \mathrm{C}$ and particle size analysis confirmed the stability of the AB-N during 6-month storage. In general, nanoemulsions containing the smallest globules (usually 100- $500 \mathrm{~nm}$ ) tend to be most physically stable. ${ }^{17}$ Our data demonstrated a stable formulation that could maintain the size even in critical storage conditions $\left(25^{\circ} \mathrm{C}\right)$.

Chemical stability studies were performed on formulations stored at room temperature and at $4{ }^{\circ} \mathrm{C}$ evaluating drug precipitation. Figure 5 reports $\mathrm{AB}$ content in the different storage conditions of $\mathrm{AB}-\mathrm{N}$ as a function of time, expressed as percentage of initial drug content. It was found that $\mathrm{AB}-\mathrm{N}$ could maintain $90 \%$ of $\mathrm{AB}$ stability for 6 months. It is to be underlined that in the present study, AB-N were stable both physically and chemically, probably because of the use of high purity soybean phosphatidylcholine.

The in vitro efficacy of $\mathrm{AB}-\mathrm{N}, \mathrm{AB}-\mathrm{DOC}$, and $\mathrm{AB}$ solubilized by DMSO was evaluated by the inhibition of Candida albicans growth. $\mathrm{AB}$ in DMSO and AB-DOC showed weaker antifungal activity than did AB-N (Table 1). This suggests that $A B-N$ retains the potent activity of $A B$ against fungal cells even though the $A B$ is incorporated into nanoemulsion particles. Therefore, $A B-N$ in the presence of fungal cells might be expected to release $A B$ in sufficient amounts. Carrillo-Munoz et al. ${ }^{18}$ showed that the release of $\mathrm{AB}$ from a lipossomal formulation (AmBisome ${ }^{\circledR}$ ) was slow and slight and the $\mathrm{AB}$ retained by lipossomes might be unable to show its strong antifungal activity, even though AmBisome ${ }^{\circledR}$ can deliver high levels of $\mathrm{AB}$ to the infected site. The mechanism of $\mathrm{AB}$ transfer from lipid formulations to fungal cells is not well understood. Fukui et al. ${ }^{19}$ assumed that the difference in antifungal activity between AmBisome ${ }^{\circledR}$ and lipid nano-sphere containing $\mathrm{AB}$ results from a selective transfer of $A B$ regulated by the physicochemical characteristics of the carrier and the target cells. According to our results, $\mathrm{AB}-\mathrm{N}$ in the presence of fungal cells readily releases $\mathrm{AB}$ because the drug has a higher affinity for ergosterol than for lipid components of the nanoemulsion.

The physicochemical data obtained in the present study suggest that this nanoemulsion system shows an attractive potential as drug delivery system. Advantages of this technique are ease of manufacturing, use of biocompatible components for parenteral administration, and production in aqueous media avoiding organic solvents. We therefore believe that further evaluation of this new $\mathrm{AB}$ delivery system is merited.

\section{ACKNOWLEDGEMENTS}

The authors thank Dr. J. I. dos Santos from the Mycology Laboratory of the Centro de Ciências da Saúde, Universidade Federal de Santa Catarina, for kindly supplying the $C$. albicans inoculum and Bristol - Meyers Squibb (São Paulo, Brazil) for amphotericin B. This work received financial support from Coordenação de Aperfeiçoamento de Pessoal de Nível Superior (Capes).

\section{REFERENCES}

1. Mora-Duarte, J.; Betts, R.; Rotstein, C.; Colombo, A. L.; Thompson-Moya, L.; Smietana, J.; Lupinacci, R.; Sable, C.; Kartsonis, N.; Perfect, J.; N. Engl. J. Med. 2002, 347, 2020.

2. Gerbaud, E.; Tamion, F.; Girault, C.; Clabault, K.; Lepretre, S.; Leroy, J.; Bonmarchand, G.; J. Antimicrob. Chemother. 2003, 51, 473.

3. Schöffski, P.; Freund, M.; Wunder, R.; Petersen, D.; Köhne, C. H.; Hecker, H.; Schubert, U.; Ganser, A.; Br. J. Pharmacol. 1998, 317, 379.

4. Bolard, J.; Joly, V.; Yeni, P.; J. Liposome Res. 1993, 3, 409.

5. Bolard, J.; Seigneuret, M.; Boudet, G.; Biochim. Biophys. Acta 1980, 599, 280.

6. Cagnoni, P. J.; Walsh, T. J.; Prendergast, M. M.; Bodensteiner, D.; Hiemenz, S.; Greenberg, R. N.; Arndt, C. A. S.; Schuster, M.; Seibel, N.; Yeldandi, V.; Tong, K. B.; J. Clin. Oncol. 2000, 18, 2476.

7. Souza, L. C.; Maranhão, R. C.; Schreier, S.; Campa, A.; J. Antimicrob. Chemother. 1993, 32, 123.

8. National Committee for Clinical Laboratory Standards; Approved standard M27-A, 1997.

9. Souza, L. C.; Campa, A.; J. Antimicrob. Chemother. 1999, 44, 77.

10. Aramwit, P.; Yu, B. G.; Labasanifar, A.; Samuel, J.; Kwon, G. S.; J. Pharm. Sci. 2000, 89, 1589.

11. Tabosa do Egito, E. S.; Araujo, I. B.; Damasceno, B. P. G. L.; Price, J. C.; J. Pharm. Sci. 2002, 91, 2354.

12. Kawabata, M.; Onda, M.; Mita, T.; J. Biochem. 2001, 129, 725.

13. Tabosa do Egito, E. S.; Fessi, H.; Appel, M.; Barrat, G.; Legrand, P.; Bolard, J.; Devissaguet, J-PH.; Int. J. Pharm. 1996, 145, 17.

14. Washington, C.; Adv. Drug Delivery Rev.1996, 20, 131.

15. Silvestri, S.; Wu, L.L.; Browser, B.; J. Parenter. Sci. Technol. 1992, 81, 413.

16. Floyd, A. G.; Pharm. Sci. Technol. Today 1999, 2, 134

17. Ishi, F.; Sasaki, I.; Ogata, H.; J. Pharm. Pharmacol. 1990, 66, 1.

18. Carrillo-Munoz, A. J.; Quindos, G.; Tur, C.; Ruesga, M. T.; Miranda, Y.; Del Valle, O.; Cossum, P. A.; Wallace, T. L.; J. Antimicrob. Chemother. 1999, 44, 397.

19. Fukui, H.; Koike, T.; Nakagawa, T.; Saheki, A.; Sonoke, S.; Tomii, Y.; Seki, J.; Int. J. Pharm. 2003, 28, 101. 